\title{
Desafios na Formação de Professores de História'
}

\author{
Antonia Terra de Calazans Fernandes \\ Departamento de História da Faculdade de Filosofia, Letras e Ciências Humanas da Universidade de São Paulo
}

* Autora para correspondência: antoniacalazans@gmail.com

\section{RESUMO}

O presente artigo debate alguns desafios na formação de professores de História, no curso de Licenciatura, considerando a importância da integração entre fundamentos teóricos e práticas educativas. Por um lado, a formação universitária possibilita profundidade teórica para o futuro docente questionar as conjunturas históricas, no esforço de análise e posicionamentos para que se insira nos contextos educacionais com atitudes ativas e reflexivas. Ao mesmo tempo, alguns gestores da educação fazem críticas aos estudos teóricos da formação universitária, como se fossem excessivos diante da necessidade de ensinar aos docentes vindouros as atividades práticas educativas cotidianas. $\mathrm{O}$ artigo combate, então, a ideia de que as práticas de ensino sejam dissociadas de concepções teóricas que fundamentam as escolhas das linhas metodológicas e contesta a premissa de que os professores sejam apenas profissionais aplicadores de atividades em sala de aula. Ao contrário, diante da complexidade das finalidades educativas, das situações sociais dos estudantes e de suas famílias e das conjunturas escolares, este trabalho defende o fato de que os docentes assumem inúmeras responsabilidades intelectuais, sociais, políticas e práticas que demandam inúmeras reflexões e decisões. E, nesse sentido, os formadores de professores também assumem a responsabilidade de propiciar estudos e vivências de situações de ensino e aprendizagem que favoreçam uma formação reflexiva e autônoma para os futuros educadores.

Palavras-chave: Ensino de História; Formação de Professores; Licenciatura.

\begin{abstract}
This article discusses some challenges in the formation of history teachers in the teaching degree course, considering the importance of integration between theoretical and educational practices. On the one hand, university education provides theoretical depth for future teachers to question the historical junctures, in the effort of analysis and positions so that they can enter into the educational contexts with active and reflective attitudes. At the same time, some education managers criticize theoretical studies of university education, as if the theoretical studies were excessive in view of the need to teach future teachers the practical daily education activities. Then, this article combats the idea that teaching practices are dissociated from theoretical concepts that underlie the choices of the methodological lines and disagrees the premise that teachers are only practioners of activities in the classroom. On the contrary, given the complexity of the educational purposes, social situations of the students and their families and school situations, the article argues the fact that teachers assume numerous intellectual responsibilities, social, policies and practices that require numerous reflections and decisions. In this sense, teacher educators also take responsibility to provide studies and experiences of teaching and learning situations that encourage a reflective and autonomous training for future educators.
\end{abstract}

Keywords: History Teaching; Teacher Formation; Teaching Degree.

\section{Introdução}

Formar professores de História é um desafio que envolve muita responsabilidade. Os temas escolhidos para o estudo, a bibliografia, os enfoques fazem diferença na formação do futuro educador. As atividades e os autores estudados criam memórias e são referências em momentos importantes quando os licenciandos assumem profissionalmente a formação de crianças e adolescentes nas escolas. Assim, o que privilegiar no curso de formação de professores de História? Quais enfoques teóricos? Entre os temas, é recomendável estudar a estrutura institucional onde irão trabalhar? O papel social da educação? A escola como instituição que inaugura cultura e prática específicas? A história da disciplina escolar e suas práticas? Os currículos atuais e oficiais 
e suas transformações históricas? A finalidade do planejamento escolar e como organizá-lo? A avaliação cotidiana nas salas de aula e as avaliações institucionais? As novas tecnologias aplicadas ao ensino? As metodologias e as didáticas? Os estudos históricos e suas possíveis interferências na construção de identidades? O valor da memória e do patrimônio? A importância de dar atenção a determinados contextos históricos? O exercício da escrita reflexiva, que contribua para consolidar e avaliar o próprio trabalho?

Talvez seja unânime a premissa de que uma das mais importantes responsabilidades do formador de professores é criar condições para a construção dos diálogos entre a teoria e a prática. Nesse caso, a formação implica estudos de explicitação de que a educação é organizada, fundamentada e praticada a partir de determinados construtores teóricos e finalidades educativas específicas, e que a definição dessas finalidades perpassa as estruturas políticas educacionais mais amplas, como também as diferentes esferas escolares, os compromissos do professor diante da sociedade e das novas gerações e, especialmente, as práticas cotidianas de sala de aula.

Os gestores escolares, perseguindo as políticas públicas normativas, muitas vezes imprimem diretrizes e modelos educacionais para os professores, sem debatê-los como circunstanciados em uma conjuntura educacional e política. Todavia, a formação universitária assume outra dimensão de profundidade, ao formar futuros docentes que aprendem a questionar essas conjunturas históricas, no esforço de análise e de posicionamentos mais críticos ante as questões, mesmo quando solicitados a aderirem a essas conjunturas nos processos educativos. $\mathrm{O}$ estudo histórico da organização dos currículos, atento aos contextos em que foram organizados, aos embates presentes em suas estruturas e ao processo em que foram implantados, contribui para que novos professores se insiram nos contextos educacionais com atitudes ativas e reflexivas.

Gestores da educação, por outro lado, costumam fazer crítica aos estudos teóricos presentes na formação universitária, como se fossem excessivos e pouco proveitosos diante da necessidade de ensinar aos docentes vindouros as atividades práticas educativas cotidianas. Contudo, o problema é apresentado como se as práticas de ensino fossem dissociadas de concepções teóricas que fundamentam as escolhas das linhas metodológicas, e como se os professores fossem apenas profissionais aplicadores de atividades em sala de aula.

Ao contrário disso, diante da complexidade das finalidades educativas, das situações sociais dos estudantes e de suas famílias e das conjunturas escolares, os docentes assumem inúmeras responsabilidades intelectuais, sociais, políticas e práticas, que demandam diversas reflexões e decisões: o que, por que e como ensinar; como concretizar propostas mais amplas em situações didáticas cotidianas; como avaliar as escolhas metodológicas; como avaliar as aprendizagens dos estudantes; como dimensionar a formação da nova geração sob a sua responsabilidade diante das questões da sociedade contemporânea.

\section{Por Que Estudar História na Escola?}

Diante da escolha de temas, de problemas e de conteúdos a serem aprofundados com os licenciandos, no curso de formação de professores de História, uma das minhas preocupações, como docente do Departamento de História da FFLCH-USP, tem sido estudar e debater o papel da disciplina dentro dos currículos. Essa escolha está associada ao reconhecimento da instabilidade do ensino de História em determinados contextos da educação brasileira. Para tanto, recorro aos estudos realizados pela professora Circe Bittencourt (1998; 2003), que, partindo de preocupações com o currículo contemporâneo, questiona o que se ensina hoje de História na escola e o que se ensinava em outras épocas, identificando distintas finalidades do estudo da disciplina, em diferentes contextos sociais e políticos nacionais.

Ela questiona:

- Qual a razão de ser da História como disciplina escolar?

- Por que estudar História na escola?

- Por que o passado, se o importante é o presente? 
- Por que a permanência da disciplina de História nos currículos oficiais?

- Se o ensino de História esteve inúmeras vezes associado à construção de identidades nacionais, e se há críticas a uma História patriótica, quais as alternativas para o estudo da História brasileira na escola?

- É possível outra abordagem do ensino de História do Brasil sem ser só o reforço à identidade nacional?

- O ensino de História do Brasil com reforço à identidade nacional sempre é alienante?

- Como estudar a História nacional diante da globalização?

- Existiram diferentes enfoques do ensino de História do Brasil na escola? Quais têm sido eles?

Assumo diante dos meus alunos, futuros professores, essas questões propostas, como uma escolha para instigá-los a perceberem as relações entre teoria e prática, e a se posicionarem diante delas. Há, de minha parte, uma preocupação de que reconheçam os currículos e as práticas educativas como históricas e dependentes de compromissos sociais e políticos dos educadores, e, assim, saibam como é importante participar dos embates e de fazer escolhas cotidianas na educação.

Com esse objetivo, currículos escolares produzidos por diferentes instituições, localidades e épocas são analisados em sala de aula pelos licenciandos, a fim de conhecerem as orientações oficiais para o ensino de História em contextos diversos, os formatos assumidos, os fundamentos educacionais defendidos, a seleção de conteúdos históricos propostos e os modos de interação no diálogo com os professores-leitores. Estudar as propostas de ensino contemporâneas, em perspectiva histórica, evidencia seus fundamentos, favorecendo debater e combater modelos fixos e predeterminados.

\section{O Que Ensinar em História?}

Estudar em perspectiva histórica também os conteúdos escolares contribui para os licenciandos refletirem sobre o que vem sendo convencionalmente disseminado no tempo presente pelas ins- tituições educacionais. Nesse caso, tenho optado por um trabalho de sala de aula, na universidade, voltado para a análise das diferentes denominações e conteúdos dados às disciplinas envolvidas com o ensino de História, em diferentes contextos da história educacional brasileira, fazendo uso principalmente da análise de livros didáticos de várias épocas e autores. Contribuem para esses estudos as pesquisas das professoras Circe Bitencourt (2004) e Arlette Gasparello (2004).

São analisados livros didáticos pertencentes ao Laboratório de Ensino e Material Didático (Lemad/História/FFLCH/USP). Esses materiais têm sido, em nossas aulas, fundamentais instrumentos didáticos para análise documental da história das disciplinas escolares, dos currículos, dos conteúdos e das relações entre a escola e a sociedade. Legislação, autores, editoras, formatos, textos, ilustrações, valores, ideologias e propostas de exercícios, relacionados aos livros, evidenciam como o ensino de história tem sido organizado em contextos variados.

Para sistematizar nossas discussões em aula, analisamos algumas abordagens de temas históricos recorrentes nos materiais didáticos. Por exemplo, avaliamos como a história das populações indígenas tem sido apresentada em diferentes épocas; ou como o Golpe de 1964 recebeu tratamento diferenciado dependendo da filiação partidária dos autores. O trabalho de análise temática nos manuais foi incentivado a partir de pesquisa da professora Thaís Nívia de Lima Fonseca (2001), publicada em artigo de livro, que confrontou os enfoques dados à Inconfidência Mineira e à imagem de Tiradentes presentes em diferentes manuais, entendendo-os como documentos históricos. Para os licenciandos, essas análises temáticas favoreceram estudar como a iconografia e os acontecimentos vêm contribuindo para consolidar a identidade da nação. Também auxiliam na constatação de que a história ensinada está em transformação ao longo do tempo. Contam como os conceitos mudam e como orientam os autores a interpretarem de modo diverso os mesmos episódios. E evidenciam como a alteração nos conceitos afeta concepções e interpretações a 
respeito dos protagonismos dos sujeitos. No caso da Inconfidência Mineira, por exemplo, os homens da ação são, dependendo do autor e do contexto do livro, designados como conspiradores, conjurados, patriotas, inconfidentes, revolucionários, idealistas ou presos políticos.

A partir da perspectiva histórica, as questões da sociedade contemporânea brasileira e suas demandas para a formação da nova geração de crianças e jovens, passam a ser debatidas nas nossas aulas como uma das preocupações para os licenciandos. Assim, eles enfrentam a questão: o que ensinar de História, para atender compromissos que acreditam ser fundamentais para a sociedade atual?

Nessa linha, como professora de História, tomo posições explícitas a favor de dar atenção a algumas questões contemporâneas que deveriam estar mais presentes nas escolas. Defendo a importância da História local, da História indígena e de afro-brasileiros e da História da América, conteúdos pouco desenvolvidos nos manuais de ensino.

A preocupação com a História local, por exemplo, tem sido trabalhada em uma disciplina específica, que recebe o nome de Uma História da Cidade de São Paulo: um Desafio Pedagógico. Nela, o esforço é problematizar o cotidiano da cidade e questionar suas historicidades, ao mesmo tempo que são propostos desafios de como estudar essas questões com os estudantes de Ensino Fundamental e Médio. Intencionalmente, os temas partem da cidade do presente e recorrem aos estudos históricos do passado, procurando simultaneamente nos espaços atuais as vivências humanas de outras épocas, os elementos naturais antes visíveis no dia a dia de seus habitantes e identificar os atores urbanos - artistas, viajantes, memorialistas, historiadores, fotógrafos, geógrafos, cartógrafos... - que produziram as imagens, as memórias, as plantas da cidade e as histórias contadas e reproduzidas ao longo do tempo.

Além dos temas históricos propriamente ditos, estudamos com os licenciandos a ampliação do que se concebe como conteúdo a ser ensinado, indo além de informações e conceitos. Incluo a preocupação de planejar e ensinar conteúdos procedi- mentais e atitudinais, a partir das contribuições de Antoni Zabala (1996). No caso de conteúdos procedimentais, debatemos situações didáticas de leitura compartilhada e procedimentos de análise de documentos históricos, como material de ensino escolar, considerando suas diferentes materialidades e linguagens. Essas atividades são recorrentes nas aulas e aprofundadas em momentos específicos junto com o estudo também de metodologias e estratégias de ensino de História.

\section{Como Ensinar História na Escola?}

O uso de documentos no estudo de História é um dos temas valorizados na formação do licenciando, com o foco no diálogo entre conhecimento histórico e conhecimento escolar. Trata-se ainda de um material com bom potencial de estudo na escola por favorecer a adoção de procedimentos metodológicos e didáticos pelo professor para as situações de ensino e aprendizagem e por propiciar estudo de conteúdos procedimentais, importantes na formação de jovens em idade escolar, que podem aprender a ler e interpretar textos, imagens, tabelas e mapas, presentes na diversidade de produções da sociedade em seu cotidiano.

No reforço do uso de documentos históricos no ensino, o curso oferecido por meio da disciplina Ensino de História, no DH/FFLCH/USP, está organizado para proporcionar também visitas ao Arquivo Público do Estado de São Paulo, ao Museu de Arqueologia e Etnologia da USP - MAE e ao Instituto de Estudos Brasileiros - IEB.

Em contextos favoráveis, a partir das disciplinas relacionadas ao ensino de História, são também realizados estudos do meio. Temos feito visitas a quilombos, aldeias indígenas e diferentes espaços da cidade de São Paulo. Nessas ocasiões, além das vivências em espaços sociais, sempre instigantes, também são debatidos procedimentos metodológicos de estudo de campo e uso de cadernos organizados para orientar registros e questionamentos.

Para problematizar as situações de ensino e aprendizagem, o curso tem desenvolvido, em determinadas circunstâncias, situações de práticas escolares, sempre as entendendo como ocasiões 
de pesquisa e de experimentação de etapas do trabalho docente, incluindo, assim, em nossas aulas, planejamento, criação de atividades e oferecimento de oficinas para alunos da escola básica. Nesse trabalho, inicialmente há um momento de organização de atividades diagnósticas pelos licenciandos; depois, a visita às escolas, com apresentações e aplicação das atividades; na sequência, na universidade, realizamos a análise dos conhecimentos prévios dos alunos e das condições de ensino e aprendizagem do contexto escolar visitado. A partir do que os alunos demonstram saber, os licenciandos planejam e estruturam oficinas, que são desenvolvidas nas escolas no final do semestre.

Tem sido sempre proposto, durante o curso, que as atividades de ensino de História envolvam metodologias de uso de documentos. Para isso, costuma-se dedicar uma aula ao estudo mais específico de como utilizá-los. Há também uma constante recorrência de leitura e análise de textos, imagens e mapas, com o propósito de estimular essa prática na escola. Essa constância instigou a busca de uma coerência entre um tema histórico, as atividades didáticas e os documentos utilizados como exemplos. A preocupação é garantir o aprofundamento de determinado conteúdo, tratado nos exercícios didáticos, fugindo de exemplos com temas variados e abordagens superficiais de seus conteúdos. Essas reflexões desencadearam uma reorganização da disciplina Ensino de História, transformando-a em um curso também temático. Ou seja, ela fica associada às questões referentes a ensino e aprendizagem de uma determinada temática histórica, diferenciada a cada ano. Nesse caso, são incluídos na bibliografia textos para aprofundamento de conceitos, problemáticas e abordagens do tema histórico, bem como também ganha espaço a análise de livros didáticos, filmes e HQs. Isso favorece a maior compreensão do contexto de procedência dos documentos históricos analisados, dos temas das leituras literárias, dos filmes debatidos e dos documentos dos arquivos e museus visitados.

A primeira experiência em tematizar o ensino de História no curso da Licenciatura ocorreu em 2014. Por conta dos cinquenta anos do Golpe de
1964 no Brasil, foram entrelaçadas às questões de ensino também a história e a documentação do regime militar. Em 2015, por causa dos setenta anos do fim da Segunda Guerra Mundial e da parceria com o Núcleo de Consciência Negra da USP, a temática foi o racismo, os genocídios e os direitos da diversidade dos povos de viverem sem discriminação e preconceitos. Em 2016, dois temas foram privilegiados: História e Gênero e História das populações indígenas brasileiras.

\section{Como Planejar o Que se Ensina?}

Uma das preocupações da disciplina Ensino de História que ministro é orientar os licenciandos no planejamento de atividades de aula. Os estudos propostos, nessa perspectiva, estão voltados para diferentes finalidades. Uma delas é proporcionar uma formação ampla das responsabilidades docentes, a qual inclui planejar os modos de realização e os objetivos das situações de ensino que serão desenvolvidas nas salas de aula, considerando fundamentação teórica, seleção de conteúdos, atividades, materiais didáticos e referências bibliográficas.

Outra preocupação é que o licenciando saia do curso já com uma proposta que o favoreça em situações profissionais, ou seja, um planejamento que ele possa apresentar quando ingressar como docente na escola, e que demonstre seus domínios pedagógicos. Nesse caso, o modelo de planejamento estudado é a sequência didática, proposta por Antoni Zabala (1996), com orientações para que sejam consideradas muitas dimensões que interferem na situação educativa. Segundo esse autor, a sequência didática inclui:

- a definição da função social do ensino, da sua intenção educativa, e sua coerência entre intenções, conteúdos e situações de ensino e aprendizagem;

- a pertinência de cada atividade no seu conjunto;

- um sentido articulado e estruturado das atividades dentro da sequência;

- a coerência da concepção de ensino e aprendizagem com as atividades propostas para serem desenvolvidas;

- e se, no seu conjunto, a proposta contempla situações que criam vivências diversificadas para 
os alunos e estudos de conteúdos diferenciados (informações, conceitos, procedimentos e atitudes).

Além disso, a fundamentação para as escolhas pedagógicas, sugeridas por Zabala (1996), está orientada para uma concepção construtivista, a partir de Piaget e Vygotsky, o que favorece o aprofundamento de estudos com os licenciandos a respeito das interações entre os sujeitos e os objetos de aprendizagem.

A proposta para os licenciandos é que a sequência didática organizada por eles, individualmente, seja o principal trabalho para avaliação do aproveitamento da disciplina, e que a sequência seja constituída por atividades estruturadas a partir de metodologias de trabalho com documentos históricos. Além disso, todos os materiais didáticos a serem utilizados devem estar inclusos ou anexados. A ideia ainda é que a sequência seja escrita de modo que outro professor possa desenvolvê-la em seu contexto escolar, considerando que, na escrita para o outro, o licenciando enfrente o desafio de explicitar ao máximo as intenções educativas, as orientações para cada atividade, e fundamente suas escolhas e referências teóricas. Há ainda a proposta de as sequências didáticas bem elaboradas serem divulgadas no site do laboratório de ensino (Lemad-História - http://lemad.fflch.usp.br/).

A divulgação dos trabalhos dos licenciandos no site contribui para que o aluno atribua outra função social à sua produção universitária, ampliando suas motivações para a elaboração do trabalho, indo além do desejo de aprovação na disciplina. Por sua vez, a presença dos materiais no site também favorece que as produções individuais sejam socializadas com os demais colegas do curso e com os professores de História em geral.

\section{Conclusão}

Minha experiência, como docente da universidade, que tem a responsabilidade de formar professores de História, vem demonstrando o quanto é importante estudar a história da disciplina escolar, a história dos materiais didáticos, a história das metodologias e didáticas, a história dos currículos, na perspectiva também de associar cada contexto do ensino, e de suas práticas, às suas finalidades e bases teóricas que fundamentam as proposições. Com essas preocupações, acredito que o futuro professor pode aprender a reconhecer que:

- há transformações históricas nos processos de ensino e aprendizagem, nos conteúdos e nos objetivos da escola e das aulas, escapando da ideia de que existem apenas modelos fixos a serem implantados;

- as propostas feitas no universo da educação contemporânea determinam fundamentos teóricos que orientam a prática, e, nesse sentido, é fundamental estudar as bases teóricas e os princípios do que tem sido proposto para ser desenvolvido (e praticado), considerando que o professor deva ser um profissional consciente e responsável pelo trabalho que desenvolve;

- o conhecimento pedagógico e didático, por seguir diferentes bases teóricas e passar por mudanças históricas, deve ser objeto de análise e escolhas conscientes e contínuas em cada contexto escolar; e

- existe um diálogo histórico, com permanências e mudanças nas tradições do ensino de História, reverberando no que é, como é, e por que é ensinado, para ser continuamente questionada a coerência entre a teoria e a prática.

\section{Nota}

1 Texto apresentado no IX Encontro Nacional Perspectivas do Ensino de História e IV Encontro Internacional do Ensino de História, Belo Horizonte, UFMG, 18 a 21 de abril de 2015 .

\section{Referências Bibliográficas}

BITTENCOURT, Circe. O Saber Histórico na Sala de Aula. São Paulo: Contexto, 1998.

Ensino de História: Fundamentos e Métodos. São Paulo: Cortez, 2004.

"Identidade Nacional e Ensino de História do Brasil". In: KARNAL, Leandro (org.). História na Sala de Aula: Conceitos, Práticas e Propostas. São Paulo: Contexto, 2003.

FERNANDES, Antonia Terra de Calazans. "Visitas a Museus e o Ensino de História". In: CUNHA, Ana Maria de Oliveira et al. (orgs.). Convergências e 
Tensões no Campo da Formação e do Trabalho Docente. Belo Horizonte: Autêntica, 2010, pp. 466-484.

FONSECA, Thais Nivia de Lima e. "Ver para Aprender: Arte, Livro Didático e a História da Nação". In: SIMAN, Lana Mara de Castro \& FONSECA, Thaís Nívia e (orgs.). Inaugurando a História e Construção da Nação: Discursos e Imagens no Ensino de História. Belo Horizonte: Autêntica, 2001, pp. 149-170.

GASPARELLO, Arlette Medeiros. Construtores de Identidades: a Pedagogia da Nação nos Livros Didáticos da
Escola Secundária Brasileira. São Paulo: Iglu, 2004.

OLIVEIRA, M. A. T. \& RANZI, S. M. F. (orgs.). História das Disciplinas Escolares no Brasil: Contribuições para o Debate. Bragança Paulista: Edusf, 2003.

- História das Cidades Brasileiras. São Paulo: Melhoramentos, 2012. Coleção Como Eu Ensino.

ZABALA, Antoni. "Os Enfoques Didáticos". In: COLL, César; MARTÍN, Elena et al. (orgs.). O Construtivismo em Sala de Aula. São Paulo: Ática, 1996, pp. 153-196.

Publicado em 30/06/2017. 